\title{
Makers Marks: Capturing, Preserving, and Sharing the Sounds of Glassmaking
}

\author{
Lisa Naas ${ }^{1, *}$ and David Faleris ${ }^{2}$ \\ 1 School of Design, Edinburgh College of Art, University of Edinburgh, Edinburgh EH3 9DF, UK \\ 2 Independent Composer, Glasgow G12 9SW, UK; faleris@gmail.com \\ * Correspondence: LNAAS@icloud.com or s1347257@sms.ed.ac.uk
}

Received: 30 November 2018; Accepted: 24 January 2019; Published: 30 January 2019

\begin{abstract}
The Makers Marks Collaborative, an international team of glass artists, visual designers, composers, and engineers, embarked on a project together from 2015-2016 to use the glassmaking studio as a staging ground for interdisciplinary, collaborative making. The team aimed to capture and preserve the sounds of traditional studio glassmaking, and then to share them outside the workshop domain through digital technologies and glass art objects. The goal was also to fulfill a public engagement grant from the Royal Academy of Engineering to highlight the engineering through the art and the engineers' vision within the art making. The team recorded and isolated the unique sounds of the glassblowing process and its studio environment, and then used the resulting digital sound collection as the foundation for developing artistic outputs: a virtual instrument library, a glass object-instrument of performance, a series of glass objects translating selected virtual instruments, and a music composition. They questioned the nature and materiality of glass through dialogue between media and conversation among team members, while exploring the practice-based research question: "How can we embed our recorded sounds of the glassmaking process back into the glass itself?" This paper focuses on the collaborative, interdisciplinary making process of the team, the project outputs, and the metaphorical language that was a key process facilitation tool.
\end{abstract}

Keywords: glassmaking; glassblowing; sound design; engineering in art; interdisciplinary collaboration; research through design; metaphorical language; craft heritage; public engagement

\section{Introduction}

The sounds of traditional making processes in artist and designer studios are not easily accessible by the general public, as they are unique to the material practices of the studios. Even those public studios and museums, which offer free making demonstrations, are few and scattered, and sometimes difficult to reach ${ }^{1}$. The sounds of the making are elusive as well, due to the specialized environments, processes, and tools. Often, they are heard only by the makers themselves, and even then, they can sometimes be masked by other studio equipment noise. One of the most exclusive and ancient making processes which produces unique sounds is that of glassblowing. As a material, glass has played host to a variety of functions and innovation over the centuries, but only recently, in the past few decades, has been used regularly as a studio medium within artistic practices (Klein 2001, p. 6). Aspects of the making process, however, have not significantly changed in centuries. For instance, glassblowers today are still inflating hot glass with their breath by using pipes and traditionally-made tools to work the material, just as they did centuries ago.

1 For instance, the National Glass Centre (2013) in Sunderland offers daily, free admission and demonstrations, but has no direct, public transport option from major cities like Glasgow. 
The history of glassblowing and the specific making processes involved have been well-documented with books covering centuries of glassmaking (Vávra 1954; Klein and Lloyd 1991) and museums such as the Museo del Vetro (2019) in Murano and the Corning Museum of Glass (2002a) in New York dedicated to the history, making, and collection of glass. Videos demonstrating the making processes are numerous with the Corning Museum of Glass (2002b) even offering regular live streaming, however, the sounds-a major output of the making process-have been relatively understudied. The sounds are both evidence of the making process and remains of the process, in much the same way as is the discarded glass, cast off in the workshop bins. Yet, the sounds are as inherent to the making as the intense heat of the furnace and the smells of burning wood and paper tools used to shape the glass. The glass studios are filled with sounds: the makers' tools working the glass in various heated states, the breath of the makers inflating the glass, the glass itself under various stresses, and the heating/cooling equipment used in the processes. Glassblowers, especially beginners, even rely on the sounds of their tools on the glass to indicate material heating/cooling levels as they learn. Listening to the glass is often orally taught, but sociologist and glassmaker Erin O'Connor ( $\mathrm{O}^{\prime}$ Connor 2007, pp. 63, 71) indicates its importance in her writing. Understanding sound becomes part of the makers' tacit knowledge as they listen to the glass to identify possible stressors while they work the material. The sounds of the glass studios are an integral part of the cultural and craft heritage of glassmaking.

\subsection{Aims and Objectives}

The aims of Makers Marks were to capture, isolate, and preserve the sounds of the making processes in the glassblowing and coldworking studios, and then to share them with the public through digital technologies and glass art objects, using the captured sounds as foundational design elements. The project was interdisciplinary at its core, requiring collaborative expertise in glass, sound, and engineering. Based in Edinburgh, the lead visual designer recruited an international team of glass artists and technicians, audio engineers and composers, and electrical and computer engineers to carry out the aims and fulfill the 2015 Ingenious Award funding the work under the title of "Glass Whispers: Audio and Electrical Engineering Meets Studio Glass for Interactive, Personal Art Experiences". This grant is part of a public engagement scheme developed by the Royal Academy of Engineering to "stimulate engineers to share their stories, passion, and expertise in innovative ways with wider audiences; to develop engineers' communication and engagement skills; and to create debate between engineers and people of all ages to raise awareness of the diversity, nature and impact of engineering" (Royal Academy of Engineering 2019). The public engagement nature of the grant influenced the glass object design and vehicles through which the team ultimately shared the studio sounds.

\subsection{Contribution to Knowledge}

The project's output of a digital sound collection is the only free, publicly accessible library of glassmaking sounds that have been recorded, isolated, and processed through Binaural Auditory Scene Re-synthesis. The virtual instruments developed from the recorded glassmaking sounds are also new, as is the eight-minute, music composition derived entirely from the sounds of the making process. Additionally, the team's use of metaphorical language as a studio process facilitation tool provides insight on successful communication for interdisciplinary, collaborative practices.

\section{Recording and Isolating the Sounds of Studio Glassmaking}

The hotshop and coldworking studios of the Edinburgh College of Art Glass Department were the host environments for recording the sounds of this project (Figure 1). 


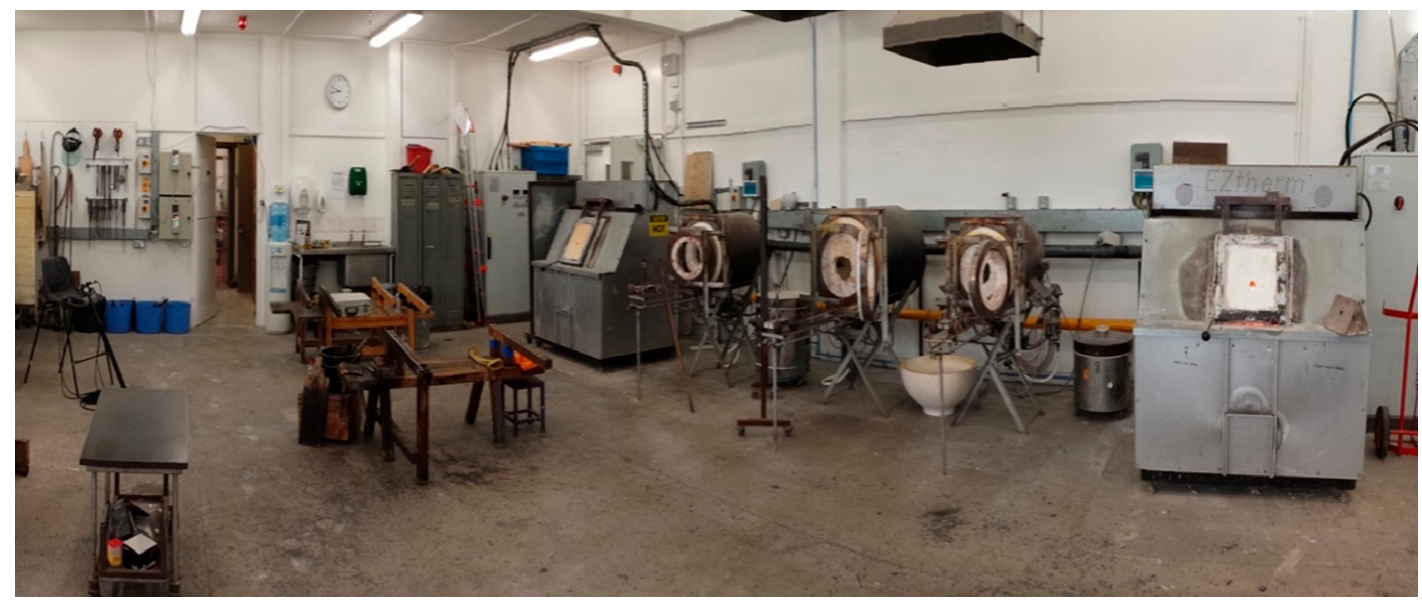

Figure 1. Panorama of the Edinburgh College of Art hotshop, the primary site for the recordings (Image: David Faleris 2015).

\subsection{Observation Day}

Before the formal recording session, the lead visual designer, the glass technician and her assistant, along with the lead audio/recording engineer and lead composer, held an "observation day" in the studios. This day served multiple purposes as it was a chance for the recording team to learn about health, safety, and protocol within the studios, to observe the making processes and test sound levels on their field recorders (Figure 2), to ask questions, and to experience a hands-on trial of working the material with the glass technician's assistance. The engineer and composer also experimented with how to maneuver themselves and their equipment around the studio without disrupting the glass workers. For the lead designer and glass technicians, the day was an opportunity to map out the formal recording session and plan the work and techniques to be recorded.

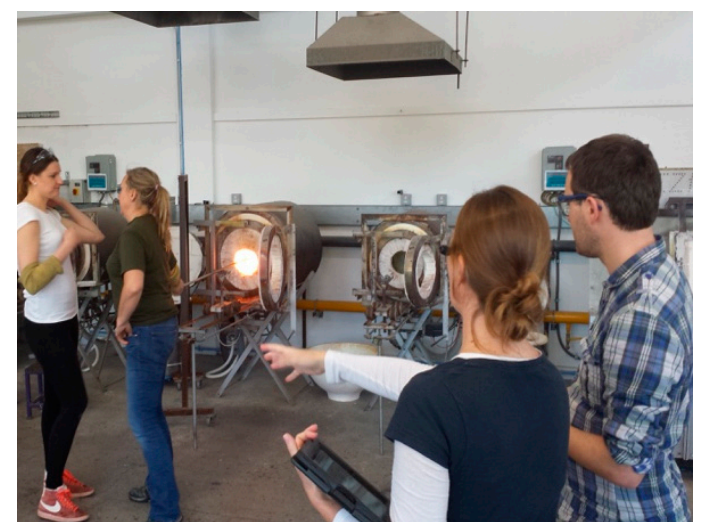

(a)

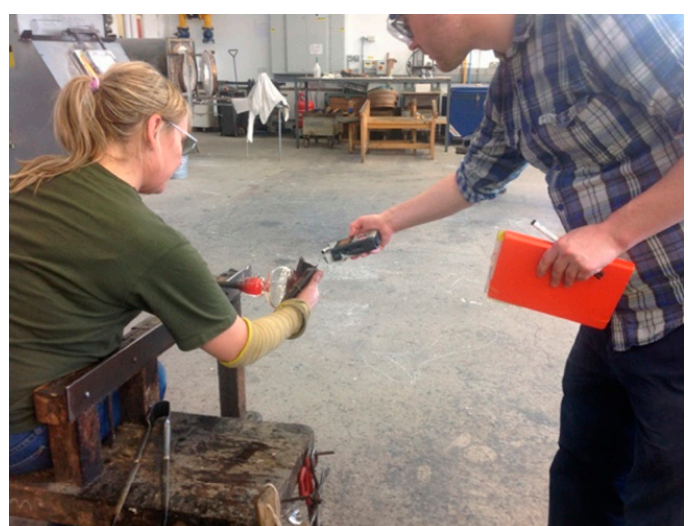

(b)

Figure 2. Observation day: (a) Shows the lead designer planning with the recording engineer on the right and the glass workers setting up a demonstration (Image: David Faleris); and (b) shows the lead recording/audio engineer recording and testing the sound levels as the glass technician shapes the glass with wet newspaper (Image: David Faleris 2015).

\subsection{Recording Session}

The recording engineer and composer employed a stereo pair of condenser microphones (Figure 3a) to capture the majority of the glassmaking sounds in high fidelity. A tiny, lavalier microphone (Figure 3b), often worn on a lapel or collar for picking up voice on stage, was also chosen to record selected techniques and environment sounds where its small size and flexible cable were beneficial. 


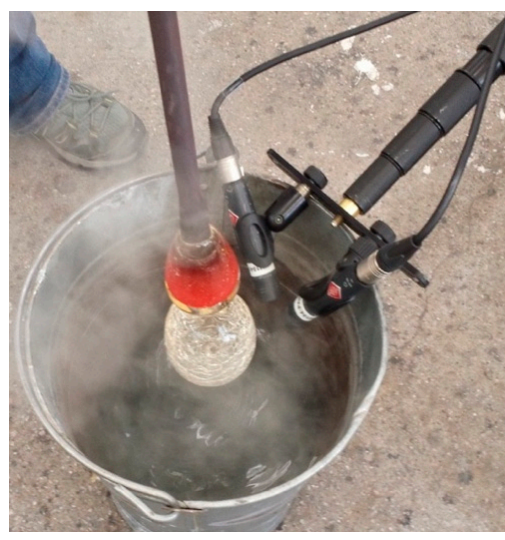

(a)

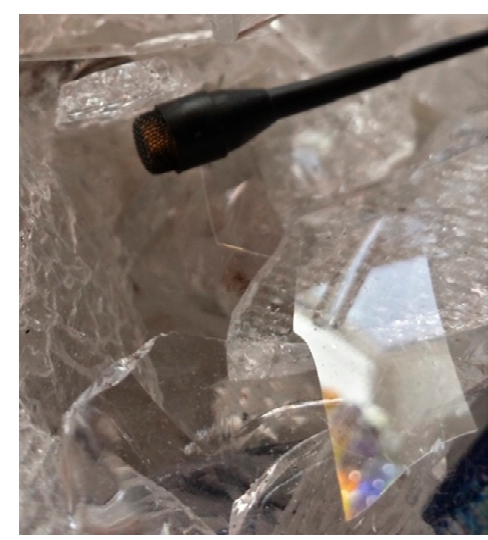

(b)

Figure 3. Recording session images highlight the two microphones: (a) Shows the much larger pair of condenser microphones on a boom, capturing the sound of hot glass flashed in water to create a crackled surface texture (Image: David Faleris 2015); and (b) depicts a tiny, lavalier microphone shown embedded in the bin where discarded, unwanted hot glass cools (Image: Lisa Naas 2015).

During the recording session, the team focused on capturing the sounds emitted by the glass, as well as the sounds of the traditional tools and techniques, with which the artists used to manipulate and shape the material in its various stages of heating and forming (Figure 4). Studio environment sounds, including equipment for heating and cooling, were also recorded (Figure 5).

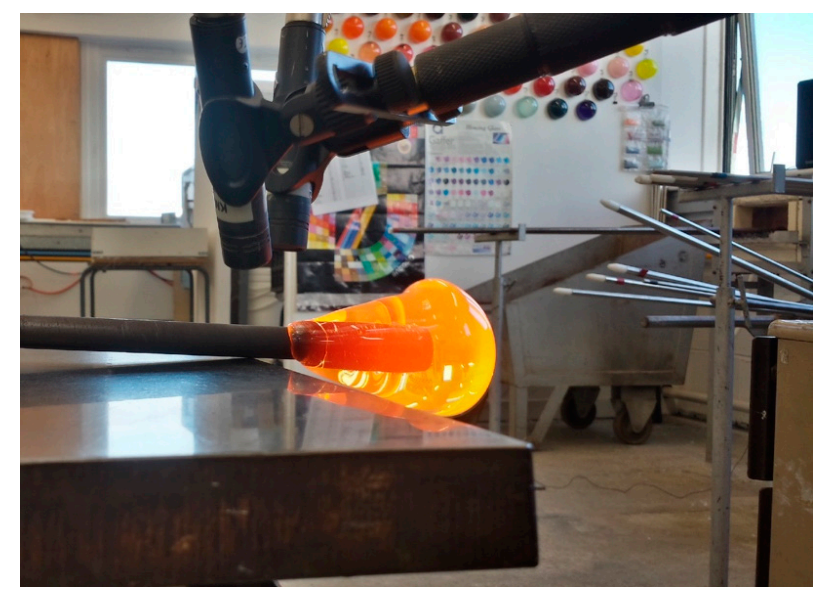

Figure 4. Capturing sounds of the glass "marvering" shaping technique (Image: David Faleris 2015).

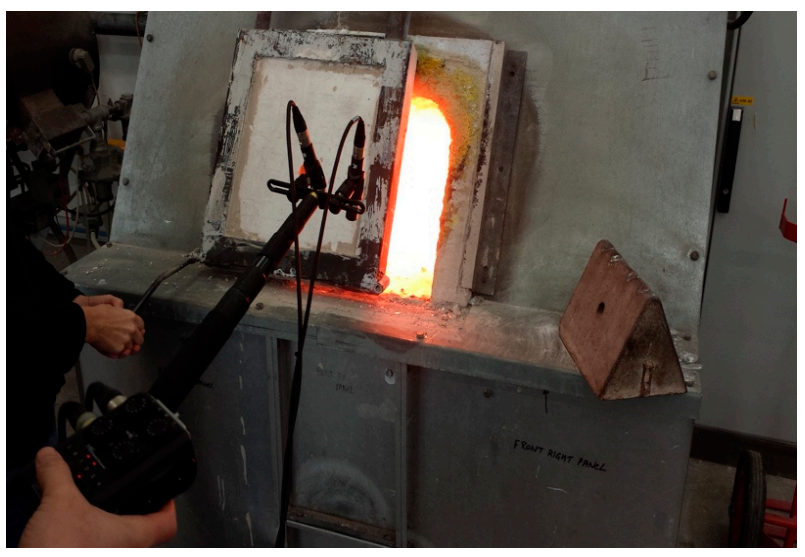

Figure 5. Recording the sound of the furnace, where the glassmakers gather the hot glass on the ends of the pipes (Image: David Faleris 2015). 
When the recording session ended, the team had captured over a hundred files of digital sound clips. All files recorded the ambient environment, but only in some did the team intentionally embrace the heavy machinery and unpredictable pops of cracking and breaking glass. Most of the recording attempts were intended to focus up close on the sounds emitted by the glass material and tools used during the making processes. Given this, the next step for the team was to clean the files of such extraneous sounds to better isolate the targets.

\subsection{Cleaning and Constructing the Digital Sound Files}

The audio engineer cleaned and isolated the target sounds from the original source audio recordings, using Auditory Scene Analysis software in development within the Informatics Department at the University of Edinburgh. As the descriptions of this technology and his process were filled with technical jargon, he found a way to explain his work to the project team by using visual metaphors, likening the auditory software to photo editing software. He used words such as sound "objects" and "masking" to describe his Binaural Auditory Scene Re-synthesis technique. Essentially, he worked with "grains" of sound in the same way that photo editor's work with pixels of colour. In a video clip from the Makers Marks (2016) documentary film for the project, Marcin Pietruszewski explains his technique this way:

It's a very similar process to what happens in vision. If you think about the virtual processes which try to model how we perceive the world visually ... the software analyzing a photo must be able to distinguish which edges of an object belong to the same object even if two objects are standing in a line or something is masking [the edge]. Basically it's a masking effect and the same phenomena occurs in our auditory perception. That we hear so many different noises but we are able to separate them into individual streams.

The challenge for him was when environmental sound obscured the target sound in the same way that an object might obscure a portion of another object in an image. In these cases, he had to add in the grains of sound that were obscured or missing, in order to achieve a full construction of the isolated source sound. He explained that his process tries to 'unmask' the sound objects.

\section{Developing Raw Sound Material}

After the audio engineer had completed his cleaning and any necessary reconstruction of the digital source sounds, the lead composer offered these sounds to an eight-member, audio engineering/sound design ${ }^{2}$ team to develop. Using digital audio workstations (DAWs) such as Logic Pro (Apple, Cupertino, CA, USA), Live (Ableton, Berlin, Germany), and Pro Tools (Avid Technology, Burlington, MA, USA), the sound designers manipulated various qualities of the source audio-ranging from the basic parameters of time, pitch, and volume, to more complex characteristics of sound, such as colour and timbre (see Figure 6). The team members approached the design of their new sounds in personal ways. Some took advantage of the percussive elements of the source audio samples to create drum kits, while others played with granular synthesis to generate glitchy, electronic synths. Some created ever-evolving soundscapes using just one source audio file, while others manipulated several different files before layering them into short, complex loops. The sound designers, working independently in various countries, returned their new sounds to the lead composer, who compiled them into a virtual instrument library. A virtual instrument, in a broad sense, is one or more audio files and/or software itself, digitally engineered to be played or programmed to serve as one sonic component of a larger music work (Jones 2017). While the cleaned source audio clips can also be used as parts of sonic works or sound effects within digital media ${ }^{3}$, these

2 In this paper, "audio engineer" and "sound designer" to identify specific team members are used interchangeably as some people held dual roles during the project or certain tasks required both expertise from the same person.

3 "Digital media" includes film, television, animation, video games, mobile apps, etc. 
newly developed sounds within the virtual instrument library were explicitly developed with music making in mind.

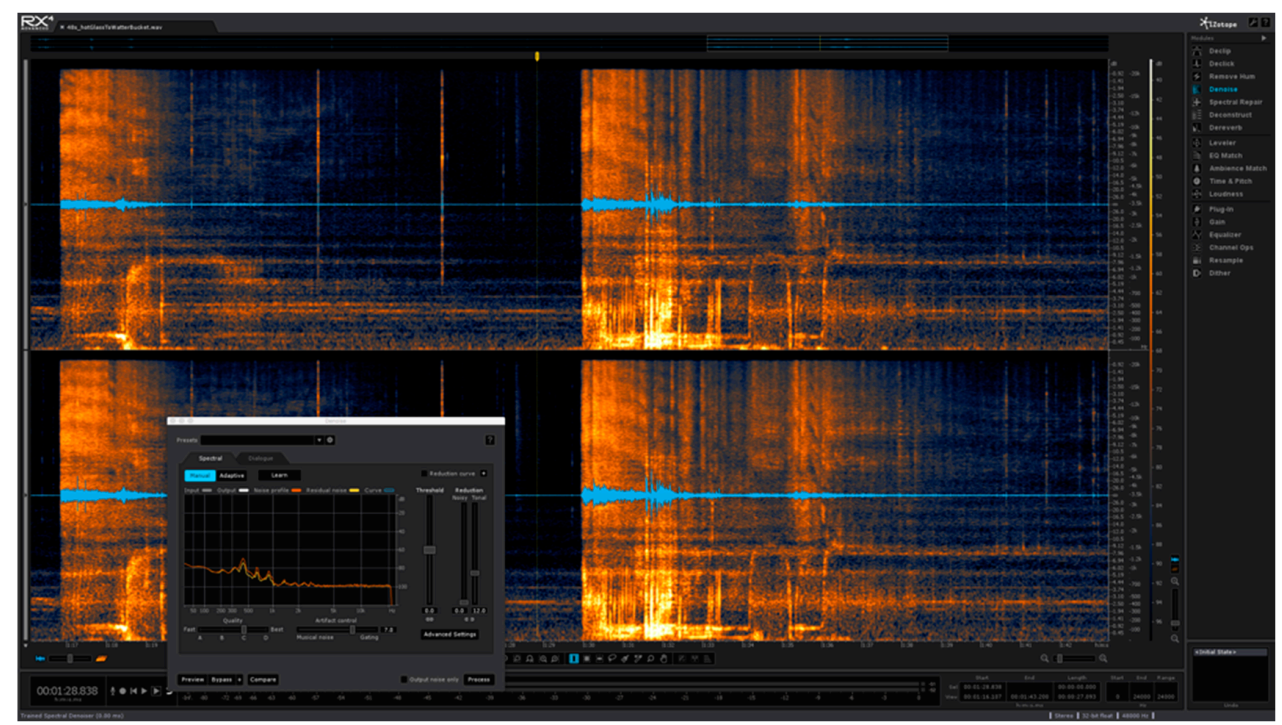

Figure 6. This is a screenshot image of RX (iZotope, Cambridge, MA, USA), one of many audio post-production tools used in audio manipulation by the sound design team (Image: David Faleris 2016).

\section{Sharing the Sounds of Glassmaking through Digital Technologies}

Glass has a more recent history of being used for sound design and special effects in digital media, as its material properties and ubiquitous nature enable sounds associated with tinkling, cracking, shattering, breaking, and scratching. The Makers Marks sound collection adds to the breadth of audio material available for use in digital media with these and additional associations. Each source audio sound and virtual instrument in the project's library collection can be used as it is for the creation of sonic works or can be further tweaked and developed by new users. There are glass sound collections and a few virtual instrument "glass" libraries available by other developers; the one created by this project team fits within that niche. For instance, United Studio Effects (2012) produced an album of glassmaking sound effects in 2012, and while open to the public and easily accessed on Amazon Music and other music websites, it is not free and does not contain engineered virtual instruments like the Makers Marks collection. Related virtual instrument libraries, such as "Glass Instruments" by the Vienna Symphonic Library (2018) and Soniccouture (2018) "Glass-Works" offer the sounds of the cold glass outputs - the final products of the glassmaking-recorded as they were played or broken or used as percussion. The Makers Marks sound collection and virtual instrument library is a new contribution to knowledge as it focuses on the sounds of the glassmaking process and is the only such open access, public library comprised of these sounds, processed with Binaural Auditory Scene Re-Synthesis.

As this Makers Marks project was underway in 2015, two other related projects were also in development: one in the United States and one in Italy. In the United States, the Wheaton Arts and Cultural Center, known for its focus on the glass medium, commissioned a new sound artwork from British installation artist Luke Jerram (Jerram 2019). The outcome was a four-minute work, titled "Keep on Turning", that features snippets of glassmaker interviews mixed with live-recorded sounds from the hotshop (Jerram 2019). The recorded sounds appear to focus on dropped, broken, and smashed glass and there is no development of virtual instruments from the original source audio recordings. Jerram also does not make any of his live-recorded sounds available, as the sole output was the commissioned sound artwork. Meanwhile, Max Casacci, the Italian composer known as Vaghe Stelle, was also recording the sounds of glass being made and broken in the furnaces of Berengo Studio on Murano (Casacci and Mana 2018; Fondazione Berengo 2018). These recordings involved 
sounds of the glassmaking process and the source audio recordings were heavily manipulated to serve a musical output. Casacci collaborated with electronic music artist Daniele Mana to produce "Glasstress", an eight-track digital album released in 2016 (Casacci and Mana 2018). Each music track uses the glass recordings as musically-developed source audio alongside a variety of synthesizers, strings, keyboards, guitars, and voice sample. While similar to Jerram, Casacci did not offer any of his glass studio recordings for purchase or open access.

The Makers Marks lead composer also created a musical output derived from sounds of the hotshop, but this output was built entirely from the sounds of glassmaking and ensuing virtual instrument development. "Makers Suite" is a complete, eight-minute, music work with every sonic element traceable back to a source audio recording of the glassmaking process. Created to mark the occasion of the project's first exhibition in October 2016, the piece can now be heard on the project's website at http:/ / www.inconcertwithglass.com/makers-suite.

Thus, while making sound effects and music from glass and glassmaking audio recordings is not wholly original and new to the field, "Makers Suite" is a new contribution in that it is a music composition derived entirely from glassmaking sounds. The audio library created from the Makers Marks project contains the only open access collection of glassmaking sounds processed with Binaural Auditory Scene Re-Synthesis, which works with sound isolation at the granular level. Additionally, the source audio and resulting virtual instruments developed during this project can now be used by other artists and designers to create standalone sonic artworks or complementary audio for visual media. The library is available for download on the project website also at http:/ / www.inconcertwithglass. com/makers-suite: Library Sets 1-4 hold the source audio files of glassmaking sounds and Library Set 5 contains the new virtual instruments created from the source audio.

The project website is designed to appeal to a wide public of all ages and backgrounds. It uses clear text, many images, and the downloadable files are in a .wav format that most computers can easily open. The site is populated with the key words of "glass", "sound", "design", "art", "engineering", and "composing" for an audience in the creative industries. Additionally, younger high school and elementary students researching various topics, or hobbyists, might also come across it and find it useful. To further the project, safeguard the work, and continue to expand the audience, the team is currently searching for a larger, more established, digital repository with which to give the sound files. Perhaps the University of Edinburgh where the project is founded would be the first place to store the files for open access, scholarly, research purposes. The team is considering cataloguing the files from both the glass perspective and the sound perspective, while also offering the files in various formats to enable the study of the sounds in different ways.

Recording, preserving, and sharing the sounds of the glassmaking process through this digital, online library collection was a goal for the team, but the group also worked to expand its reach specifically within the Edinburgh community of its host institution to engage the public with the audio engineering and engineers' stories using glass art objects as vehicles in exhibition. Creating the audio library set the foundation for the interdisciplinary, collaborative research that followed to make the objects.

\section{Sharing the Sounds of Glassmaking through Glass Art Objects}

The team regrouped once a month after the recording session for discussion about the next steps for the project. They met in the glass studios, the recording studios, and over lunch outside of the workshop spaces. During these meetings, the lead visual designer pushed the members to find common ground among the interests and disciplines represented within the team: art/design, music/sound, and engineering. The team members each had different, specific interests in the project. For instance, after working with the sounds to clean them, the lead recording/audio engineer found it sonically interesting to separate form from frequency and discussed wanting to take his model of resonance and put it in different spaces. The lead visual designer, on the other hand, was most interested in the sound material that was left as remains of the glassmaking. There were, however, shared and overlapping 
interests of the group that were noted in February 2016 meeting minutes as "interested in gesture ... the performance of working the glass". The team members also agreed that they wanted to bring the source audio and new virtual instrument sounds back to the glass itself. To organize themselves and their work around that thought, they developed the team-unifying, practice-based research question: "How can we embed our recorded sounds of the glassmaking process back into the glass itself?" The team could not come to agreement on one approach to frame a single response because the team leaders interpreted the question in different ways. Instead, the group agreed to work concurrently on two glass projects, with both taking into consideration the need to fulfill the public engagement grant by highlighting the engineering or the engineers' stories within the art. The end result was a cohesive body of work, but the differing interpretations of the research question sent the art works in separate directions, which will be discussed in each of the output descriptions. Both research outputs incorporate digital technologies, glass objects, and highlight the engineering, but the "Sounding Glass" project, a glass object/musical instrument, approached the question rather literally, while "Glass in Translation", a series of glass objects paired with sounds, investigated it more abstractly.

\section{1. "Sounding Glass": A Literal Approach to Embed the Sounds into Glass through Engineering}

"Sounding Glass" is a glass object (see Figure 7) that allows the audience to explore sounds of glassmaking by touching and handling the glass piece itself. In the average user's hands, it is a performing object that can lead the audience on a pleasant sonic adventure, while in a trained musician's hands, it can also become a calculated, musical instrument-object of performance. As such, "Sounding Glass" follows in the long tradition of musical instruments created from glass and played by hand. Musical singing glasses were known in Persia as early as the 14th century (Apel 1972). These glasses, which were often wine glasses filled with water to various levels to generate specific pitches, were played by running wet fingers along the rims. In the mid-1700s Benjamin Franklin invented the glass armonica, a musical instrument of glass bowls tuned to notes by their varying size, fitted one inside the next with cork, and played by hand with moistened fingers (The Franklin Institute 2018). Even today, orchestras and musicians such as Robert Tiso (Tiso 2018) and DuoGlass (2018) continue to showcase singing glasses and glass harps in their performances. Contemporary glass artist Carrie Fertig takes glass musical instrument making to a new, live level with her Torcher Chamber Arkestra (Fertig 2018). In Torcher Chamber performances, Fertig creates glass percussion instruments with her torch working in front of live audiences and collaborates with professional musicians, who play them as she finishes making them.

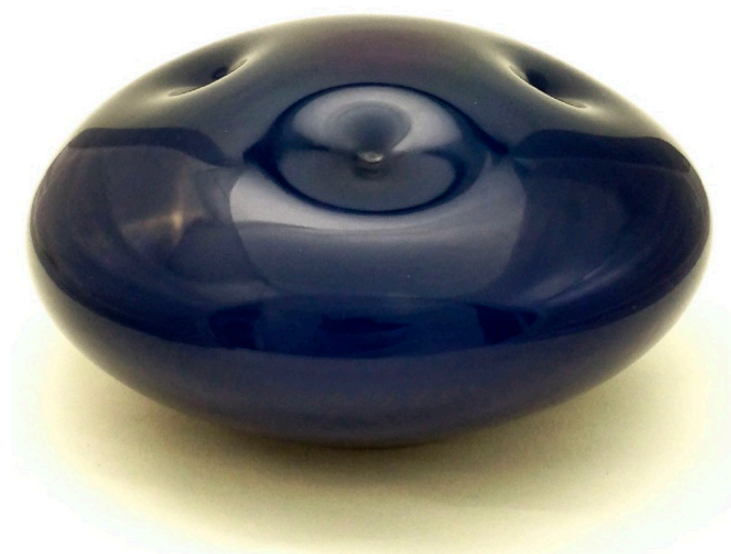

Figure 7. "Sounding Glass" is a blown glass piece with a hollow interior housing copper strips and electronics. It measures $20 \mathrm{~cm}$ high $\times 30 \mathrm{~cm}$ diameter. (Image: Lisa Naas 2016).

"Sounding Glass", while related to these other instruments, differs significantly in that the physical glass of the object is not the emitter of the instrument's musical sounds. Rather, it is an 
engineered, silent agent through which embedded sounds of the glassmaking are conveyed to the audience. The object's physical form (a convex, shallow vessel with dimples) is designed to directly reference the musical Hang or handpan, a metal instrument requiring both engineering and sonic sculpting in its making (Venuti 2018). Referencing the handpan with the object form is intended to alert the audience that the piece is played by hand. Handlers play "Sounding Glass" through touch and gesture, initiating the project's source audio recordings and/or the new virtual instrument sounds. These sounds were carefully selected and orchestrated together, sonically, to operate as one cohesive instrument of performance. The physical contact of hand on glass sends digital signals to a computer program that outputs sound to the audience through headphones (see Figure 8 ). In exhibition ${ }^{4}$, the computer program that mediates the sound is displayed alongside the glass object so that the audience can also examine its audio engineering and programming, as its numbers and meters visually fluctuate during user interaction (also Figure 8).

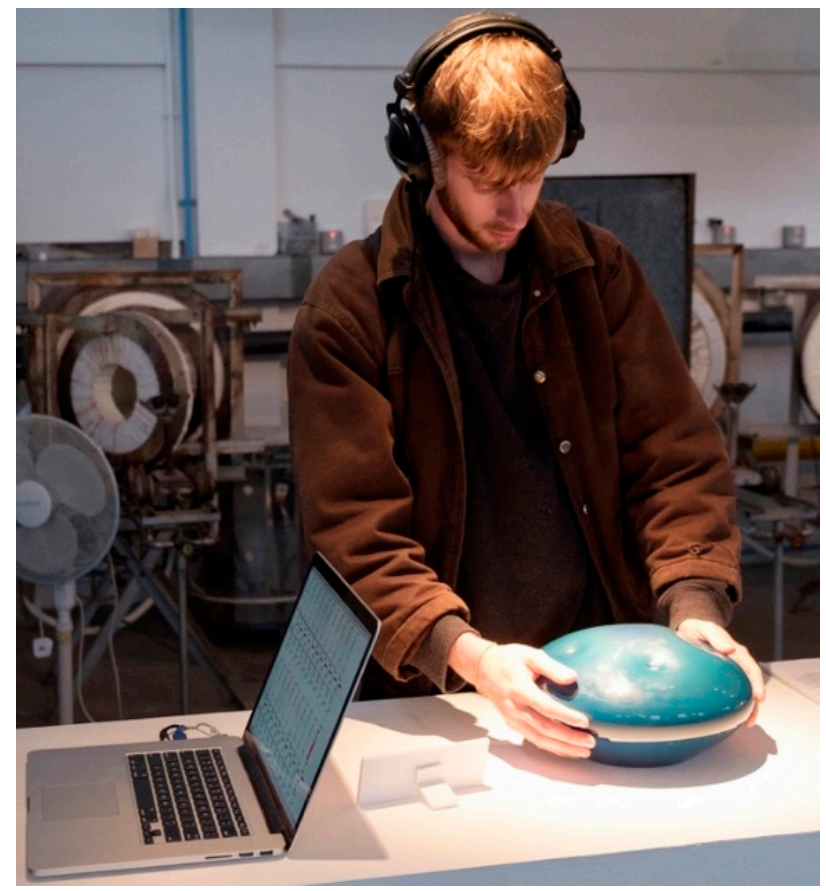

Figure 8. "Sounding Glass" played by a visitor to an open studio day in 2016 (Image: Alex Hall 2016).

\subsubsection{Making the Glass for "Sounding Glass"}

The lead designer, the lead composer, three glass artists, and one electrical engineer/computer programmer comprised the team that created "Sounding Glass". Tasks to develop the piece were initially divided according to fields of expertise, but ultimately, it took additional interdisciplinary subgroups working collaboratively to complete the work. Two prototypes were necessary before the final piece was created, but all work began in the glass studios with the artist subgroup creating the glass (Figure 9).

4 "Sounding Glass" was exhibited three times for the local Edinburgh community in 2016: (1) as part of the Contemporary Glass Society's "Time to Share" workshop at the North Lands Creative Glass Conference hosted at Edinburgh College of Art in September, (2) with the Makers Marks open studio exhibition during the Edinburgh College of Art October Open Days, and (3) in November at Summerhall in a joint networking/exhibition/public engagement event with Edinburgh Hacklab and ASCUS Art \& Science. 


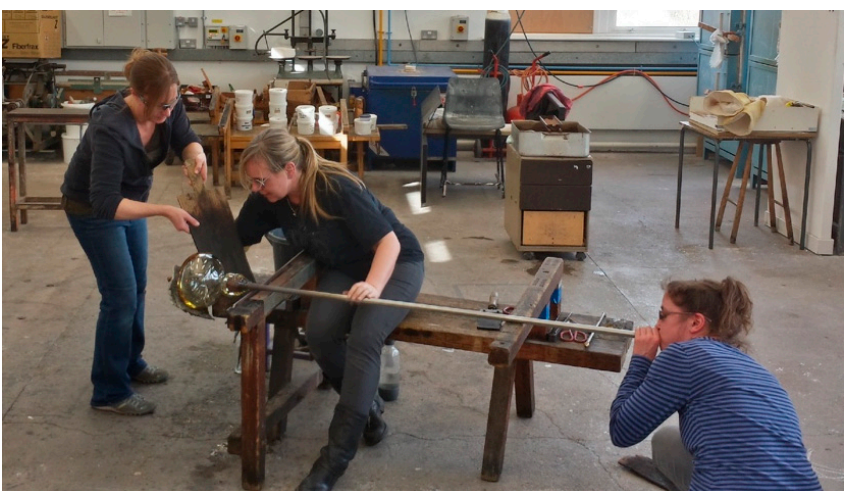

(a)

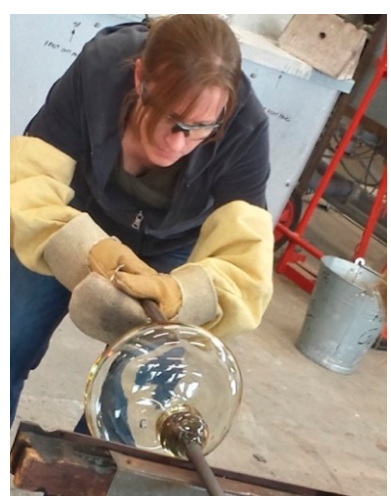

(b)

Figure 9. Developing a "Sounding Glass" prototype: (a) Shows the team shaping the overall glass vessel form (Image: David Faleris 2016); and (b) shows the detail work of forming the dimples on the surface. (Image: David Faleris 2016).

\subsubsection{Designing the Sound Touch Points for "Sounding Glass"}

The composer, with the lead designer, mapped out where they wanted the touch points to be located on the glass object (Figure 10). To identify the touch points, they handled the prototype and discussed how a visitor might approach the glass form. The four prominent dimples on the glass object were both visual and physical focus points, cues like those of a Hang/handpan (Venuti 2018). The pair decided that these should be markedly different from the other touch points. Each dimple would end up being mapped to trigger different, active and dynamic source sounds of the glassmaking process (e.g., marvering, flashing hot glass in water). The remaining topside of "Sounding Glass" was linked to various passive and static source sounds from the hotshop, such as the steady running furnace, while the underside of the object was set up to trigger selected virtual instrument sounds created by the sound design team.

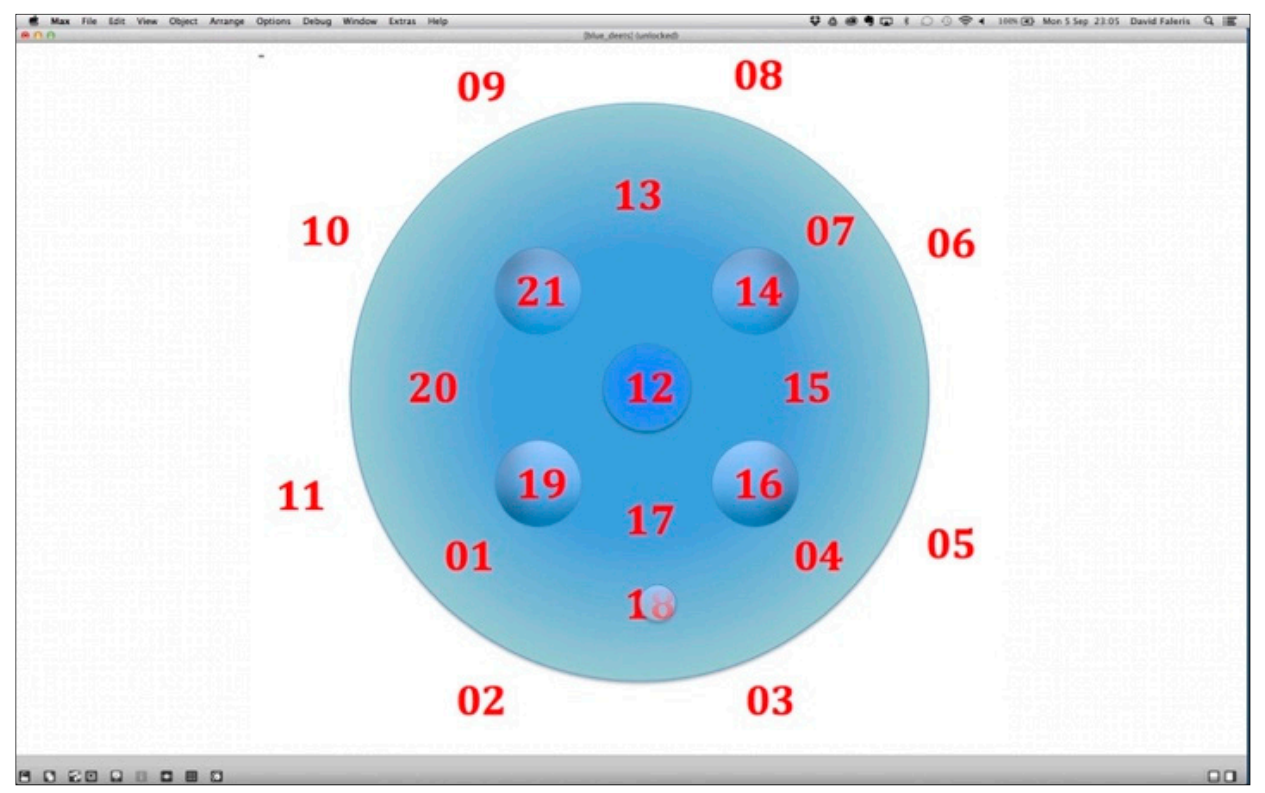

Figure 10. The composer's drawing shows the glass object from an aerial perspective and indicates the 21 touch points linked to sensors attached within the glass hollow inside. (Image: David Faleris 2016).

Every sound mapped to the object was carefully curated to ensure a harmonious playing experience. All sound volumes were adjusted to match one another, and all audio files were prepared as seamless loops so the user could hold a hand to the object without the sound ever breaking. 


\subsubsection{Making "Sounding Glass" Sound}

"Sounding Glass" works because the electrical engineer and the composer combined their skills to allow touch to trigger and alter sound. The hollow interior of "Sounding Glass" is a complex scheme of Arduino boards and electronics that use copper strips attached to the interior glass surface to conduct human capacitance-natural human electrical charge (Figure 11).

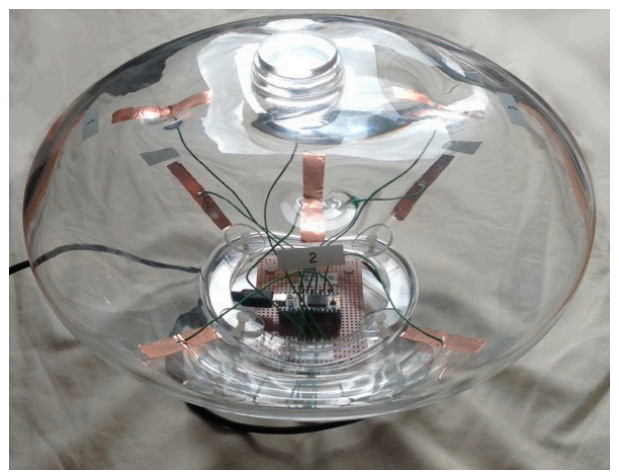

(a)

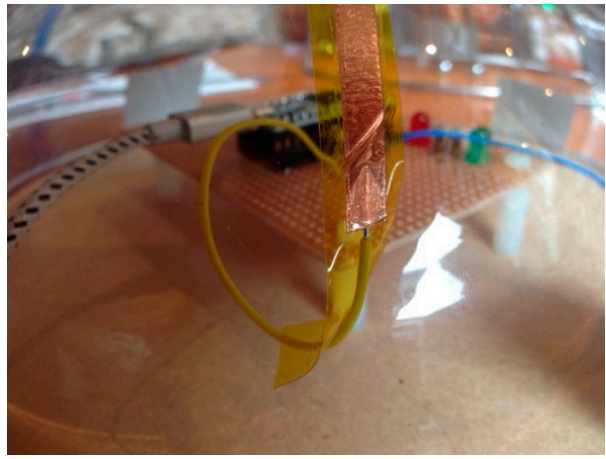

(b)

Figure 11. Prototyping "Sounding Glass" and testing copper strip capacitance: (a) Prototype II showing the entire glass piece (Image: Lisa Naas 2016); and (b) prototype I showing a close-up of a copper strip (Image: Lisa Naas 2016).

The engineer programmed "Sounding Glass" so that, when one turns it on, it reads the sensors and calibrates according to the first person that touches it and sets parameters based on that first handling. Once activated and calibrated, the capacitance drives the Max/MSP program (Figure 12), custom-built by the lead composer to run on a computer attached to the object. User touch is not pressure-sensitive; pushing harder will not make the sound louder. Rather, the amount of the copper strip covered by the user's fingers or hand directly correlates to the playback volume. The programming also includes support for common user gestures such as swiping, which further alters the handler's sound experience.

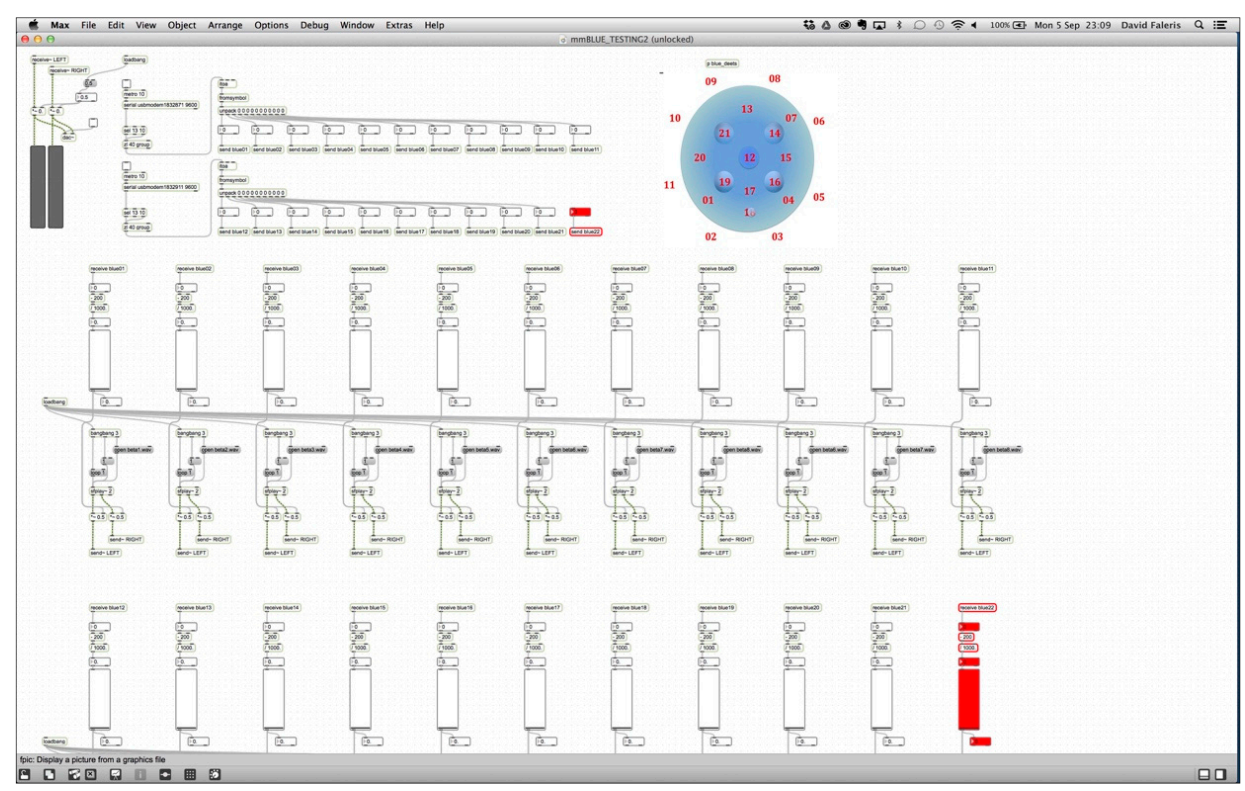

Figure 12. Max/MSP (Cycling '74, San Francisco, USA) screenshot showing real-time capacitance levels for each copper strip sensor, determining which sound files play back at correlating volumes (Image: David Faleris 2016). 


\section{2. "Glass in Translation": Abstractly Embedding the Sounds and Audio Engineering into the Glass}

"Glass in Translation" developed concurrent to "Sounding Glass", with its team interpreting the research question more loosely as a catalyst for a conceptual artwork. Academic philosophers Peter Goldie and Elisabeth Schellekens debate "concept" in art within their introduction to Philosophy and Conceptual Art and argue that if approached philosophically and inclusively, "conceptual art" has certain characteristics in common, including an emphasis on ideas (Goldie and Schellekens 2009, p. xii). Schellekens goes as far as to say that the idea is the art and that the idea is the material of the art work, relying on similar words used by conceptual artist Sol LeWitt in 1967 to develop her argument (Schellekens 2009, p. 74). Philosopher Wesley D. Cray (Cray 2014, p. 235) acknowledges that the academic consensus is that "conceptual art" is about ideas, but challenges Schellekens' more extreme view, positing instead that "conceptual artworks are not ideas but art[e]facts imbued with ideas". For "Glass in Translation", the question of "embedding" was less about literal placement of the sound in glass and more about bringing the idea of the sound back to the glass material, from where it originated. During its making, the "Glass in Translation" subproject provoked the team to question and debate the idea and nature of sound and of glass, while the final work is offered to the audience to consider the same: Is the sound in the glass? Is the glass the sound?

For "Glass in Translation" three newly developed virtual instruments from the glassmaking source audio were the focal points. The team that worked on "Glass in Translation" included the lead designer, the lead composer, three glass artists, and two audio engineers/sound designers. The project aimed to highlight the use of the metaphorical language and analogies found in the dialogue among the team members, especially that of the audio engineers as they worked to articulate their design and processes during the collaboration. The lead composer and the audio engineers each provided one of their own newly developed virtual instruments to the lead visual designer. The instruments were each delivered as a single audio file, along with a title, and a written description of the sound. The lead designer considered these her raw materials, containing the idea of the sounds, which she was to return to the glass as designed objects. Based on her personal reading, listening, and understanding of these materials, she translated all of them into sketches, using pen, paper, and Photoshop (Adobe, San Jose, CA, USA). Working collaboratively in the hotshop, she and the glass artists then realized the sketches as objects, putting the idea of the sounds back into the glass. The glass, the audio, and the written descriptions of the sounds are all displayed together when in exhibition ${ }^{5}$, with each set of glass objects corresponding to a new virtual instrument sound (Figure 13).

Musicians, composers, and audio engineers sometimes describe sound using visual language in terms such as "colour", "texture", "shape", "weight", and others (Feeney 2016), while some go as far as to refer to entire compositions as sound paintings (Levitin 2007, p. 55). This is a metaphorical way to communicate the information and is particularly useful in discussing abstract sonic concepts. It is commonplace and no longer so obvious as a metaphor, but it is visual language found within the aural. This visual language was quite common within the conversation among the team members, especially as the audio engineers and composer discussed the sounds with members from other disciplines. This visual in the aural is an intersection point between music and visual art and was the focus of this second subproject.

5 "Glass in Translation" was exhibited three times for the Edinburgh community for public engagement with engineering: (1) as part of the studio showing for the Edinburgh College of Art Open Days in October 2016, (2) in exhibition for the Summerhall networking event with Hacklab and ASCUS Art \& Science in November 2016, and (3) in the National Museum of Scotland for the 2017 Research Through Design Conference. 


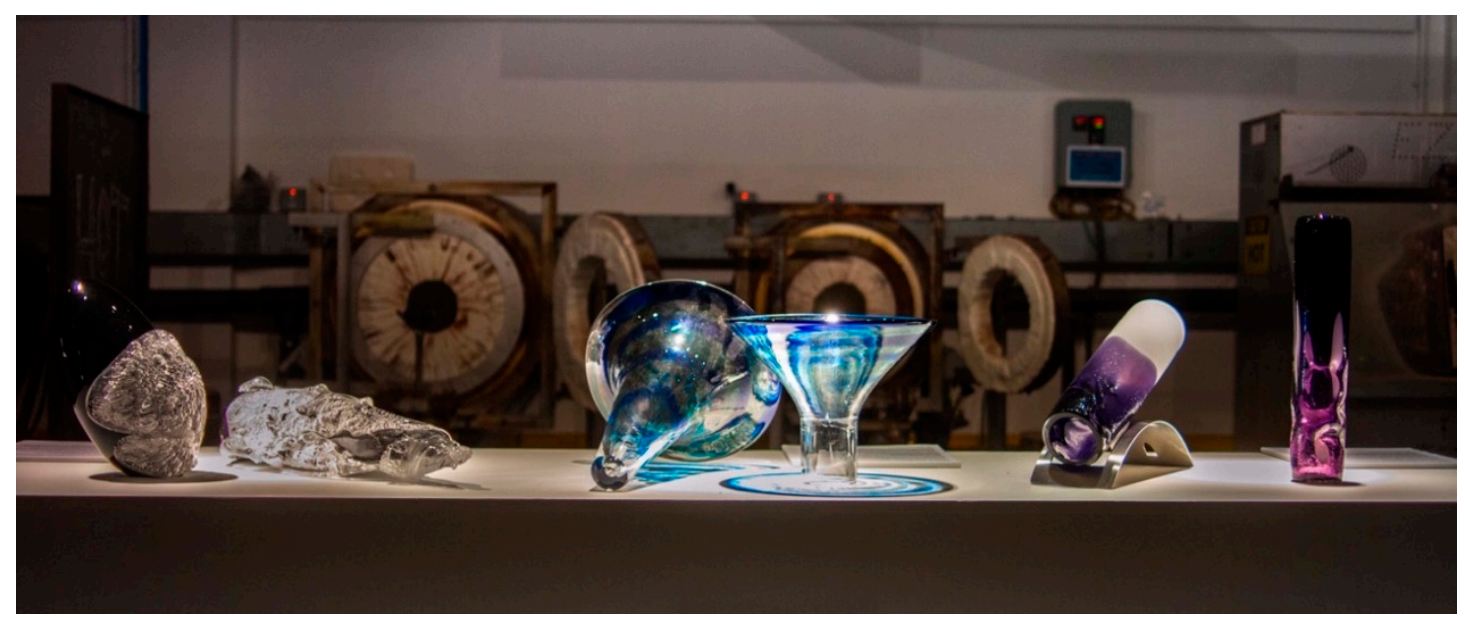

Figure 13. The full collection of glass objects that comprise "Glass in Translation". From left to right: "Italian Nightmares", “Makers Whirlpool”, and "Ewok Machine”. (Image: Alkistis Terzi 2016).

The metaphor is most widely recognized as a literary device, featuring prominently in such lyric writing as poetry and fiction. In using it, the writer describes ' $x$ ' as ' $y$ ', implying that associations with ' $y$ ' can be carried over to ' $x$ ' to offer a deeper understanding of ' $x$ '. Jan Zwicky (Zwicky 2013, p. 1), author of Lyric Philosophy and developer of lyric inquiry, describes the metaphor as "the linguistic expression of the results of focused analogical thinking". In I Is an Other, writer James Greary (2011) puts forth arguments based on historical evidence and linguistics for the metaphor being the basic building block to communication, comprehension, invention, and discovery. Greary (2011, p. 20) posits that metaphors are much more than literary devices or even devices of lyric inquiry, as he states that "metaphorical thinking is the way we make sense of the world, and every individual metaphor is a specific instance of this imaginative process at work". He asserts that "metaphors are therefore not confined to spoken or written language" (Greary 2011, p. 20). In Mental Leaps: Analogy in Creative Thought, the cognitive scientists Holyoak and Thagard $(1999$, p. 5) discuss metaphor or analogy, as "model-building in the mind to understand something in the world". They explain that carrying over associations from the source analog (the known domain with familiar, learned patterns) to the target analog (the relatively unfamiliar domain) is the essence of analogical thinking (Holyoak and Thagard 1999, p. 2). Just as Greary describes metaphor, Holyoak and Thagard (1999, p. 9) also write how this 'carrying over' develops a systematic set of correspondences between the source and the target so that one can see the thing as if it were another, "creating a tension between two perspectives: the thing as itself and the thing as something else". Most interestingly, they write that analogy by "its very nature freely oversteps the traditional boundaries between knowledge domains, making it possible to use ideas from one domain to achieve insights in another" (Holyoak and Thagard 1999, pp. ix-x). They argue that analogy allows our minds to form ideas that are "beyond sensory experience" and "out of our realm of understanding" (Holyoak and Thagard 1999, p. 10). In other words, through analogical thinking, we can understand the unknown, the unfamiliar, and the new.

Thus, metaphors are literary devices, linguistic expressions, and tools for human understanding. They are also techniques used within the creative process. Glass, with its unique blend of physical properties as well as intangible qualities and various functions in society, is well-suited for use as a visual metaphor material to help describe the new. In the case of "Glass in Translation", the virtual instruments were the new and unknown. 


\subsubsection{Describing New Virtual Instrument Sounds}

The lead visual designer requested that the sound designers and composer each choose one of their own new virtual instrument sounds and describe them to her in writing. She requested that they use the visual language and terms common to both disciplines, such as colour, shape, texture, and weight. They responded, not with synesthetic reactions ${ }^{6}$, but with thoughtful, considered responses about their new sounds. The lead composer offered the following description of his new sound as:

Funnel or cone shape, wide base ... perfectly round, perhaps slightly distorted or static-y in texture, but solid and strong. Comes up to a hollow and thin vertical pipe shape on top, clean and free of distortion/static. The color also moves from dark at the base to light on top. Dark blue/green on up to something more transparent and light. A small sweeping gesture of color runs through for one moment in the middle ... not parallel nor perpendicular, but at an angle, as if being sucked towards the top but in a circular motion ... almost like a reverse whirlpool or black hole. (Faleris 2016)

He had used several of the source sounds recorded from the glassmaking to create his new virtual instrument, which he titled "Makers Whirlpool". The composer and sound designers provided no other explanation to the lead designer and no other discussion of the new sounds took place. The lead designer spent time listening to each sound with headphones when she had the written descriptions to accompany them. Then, using the composer's and sound designers' written descriptions like the one above, along with her own experience listening to the new sounds, the visual designer created sketches for new glass pieces (Figure 14). She took these drawings, along with the words and sounds, to the glass technicians/artist team. Together, they listened to the audio files, discussed the written words as well as the sounds they were hearing, and debated how to visualize each in glass. Then they proposed and considered various techniques and approaches for realizing the sketches in glass, producing a plan for each piece before the studio work began. For each of the three sounds, they made two attempts in glass. Together these six pieces along with the three sounds comprise "Glass in Translation" (Figure 13). The glass pieces have the same titles as what the composer and sound designers offered.

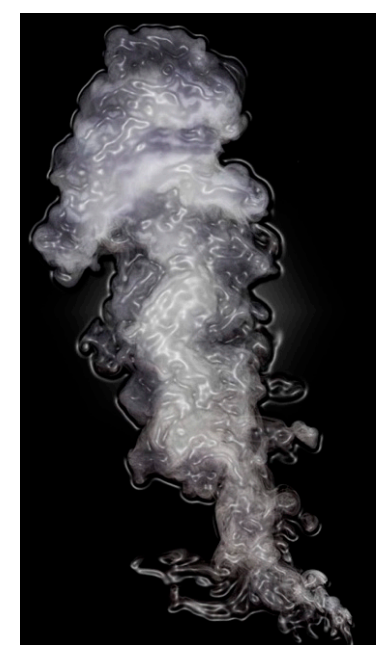

(a)

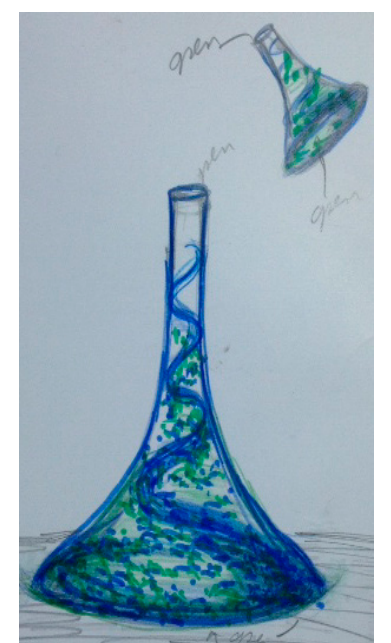

(b)

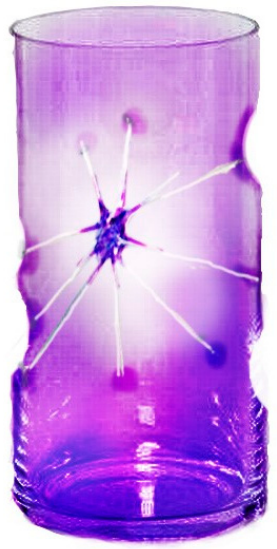

(c)

Figure 14. Sketches based on new sounds and their written descriptions: (a) Computer generated sketch for "Italian Nightmares" sound (Image: Lisa Naas 2016); (b) pencil/pen sketch for "Makers Whirlpool" (Image: Lisa Naas 2016); and (c) computer generated sketch for "Ewok Machine" (Image: Lisa Naas 2016).

6 Discussion among the team members confirmed this after the project. 


\subsubsection{Challenges and Team Responses}

Two issues-communication and traditional studio practices-repeatedly challenged the team throughout the work on the Makers Marks project, and specifically during the making of "Glass in Translation". Working across disciplines required all members to have basic knowledge of terms and language used by the group members. This was necessary in order to have productive conversations about the various processes and techniques they were using. It meant withholding assumptions and asking many questions. Additionally, as the team was working with new works in sound, the lead designer felt that it was important for the team to push away from the traditional within the glassmaking process. This was new, frustrating, and exciting for everyone involved. Most interestingly, the team instinctively turned to simile and metaphor in the conversation to respond to the challenges. "Italian Nightmares" offers a good example and some evidence to support how the team used analogy as a tool within the process of creating this work.

Sound designer Alessandro Mastroianni's description of his new virtual instrument, which was based on the source audio of wet newspaper shaping hot glass, was the most difficult for the visual team to understand:

a very heavy looking sound. Despite its weight though, it doesn't have any snapping quality, telling me that [it] is, again, rather smooth than sharp. The color of this one is a transparent, dark grey. (Mastroianni 2016)

The lack of a definitive shape was the most puzzling to work out technically. After listening to the sound and reading the composer's description, the lead designer's immediate response was to associate with the words "roiling", "patterns in boiling", and "bubbles from boiling". She tried to explain this and her sketch (Figure 14a) to the glass technicians assisting her. She asked for creative input on how to trap air within the piece. The lead glass technician suggested using a reaction between bicarbonate soda and the hot glass by sprinkling the bicarbonate soda over the piece to create bubbles as they pulled and twisted the material into a sculpture (Figure 15).

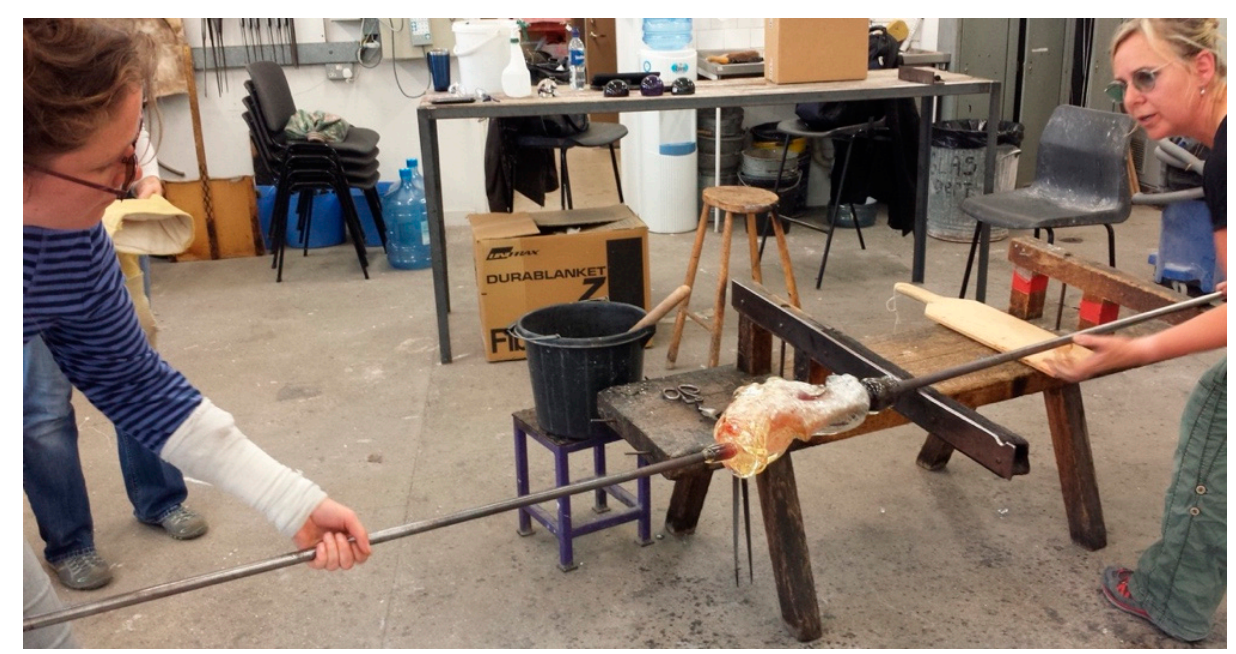

Figure 15. Two of the glass team members pulling and twisting the hot glass during the first attempt to make “Italian Nightmares" (Image: David Faleris 2016).

The result, however (shown in Figure 16), was missing an intangible quality that the team all heard in the sound, but struggled to articulate. 


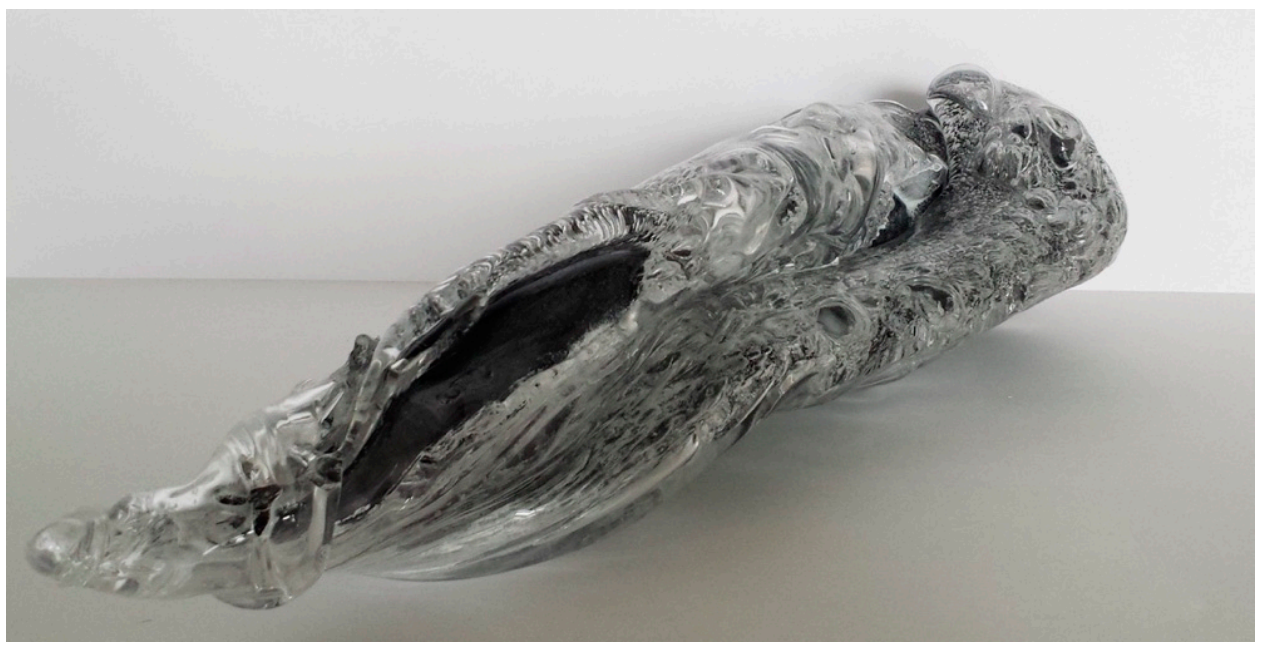

Figure 16. The glass output from the first attempt at creating “Italian Nightmares” (Image: Lisa Naas 2016).

Prior to the next attempt at making "Italian Nightmares", the visual team returned to talking about what they had heard in the sound and what that might look like in glass, while still maintaining the visuals and idea of the sound offered by the composer words. The lead designer conferred with the lead composer about the sound for his fresh ears and words. He said that Mastroianni's sound "sounded like a growing virus or an infection". His simile gave the lead designer what she needed to redesign the glass piece and attempt the work again with the technicians. She pushed hard for the group to break out of what was traditional with the glass and to exploit the material in the same way they were trying to exploit the language and the source sounds. The composer and lead designer discussed this idea of "virus" and "infection" with the technicians. The designer explained that, in glass, she thought the composer's "virus" was akin to her "roiling bubbles" overtaking the glass.

On the second setup, the glass team used an inordinate amount of bicarbonate soda to create the piece (Figure 17) and actually ended up contaminating the whole furnace pot of glass, making for major clean-up work at the end. In traditional glassmaking, bubbles are often considered as flaws. In fact, a single bubble is sometimes enough to ruin a work. Glassmaking has a deep tradition in Italy and given that the virtual instrument was entitled "Italian Nightmares", it fit the project to reconsider the bubbles that are often seen as a glassmaker's nightmare. "Italian Nightmares II" highlights the bubble growth on the smooth body of the traditionally formed glass vessel (see Figure 18) and is a play on words with the title.

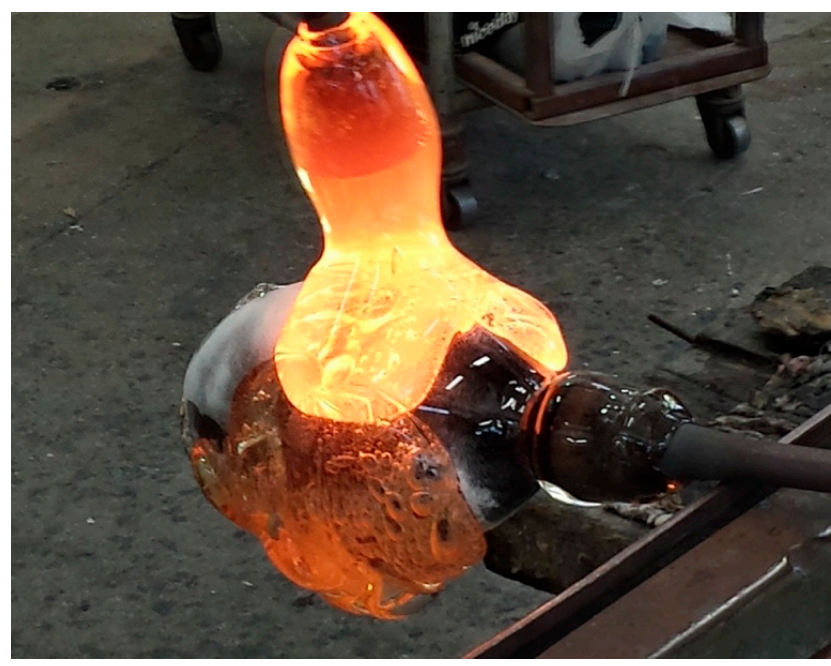

Figure 17. Making "Italian Nightmares II"; the white colour is the bicarbonate soda on the glass (Image: David Faleris 2016). 


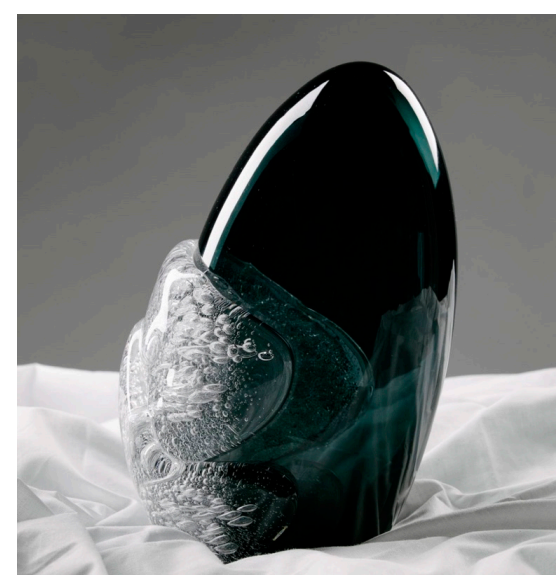

Figure 18. Portrait of "Italian Nightmares II" (Image: Alex Hall 2016).

\section{In Exhibition}

While the Makers Marks project offers images of "Sounding Glass" and "Glass in Translation", the physical object outputs are best viewed and handled in person for a full experience. During the period of the Ingenious Award, the team collaborated with a number of organisations in a variety of settings to engage the local, diverse Edinburgh community with the project and the engineering behind the artworks (see Footnotes 4 and 5, on pages 9 and 13 respectively). At all of the events, lead team members were available to discuss the project and the engineering with the visitors. Niche conferences like the 2016 North Lands Creative Glass Conference and the 2017 Research Through Design Conference drew specific audiences that were primarily academic in nature and geared toward specific themes, but other opportunities allowed more general access. Prospective arts students, parents, and staff toured the hotshop with the Makers Marks objects in exhibition at Edinburgh College of Art during its Open Days. At Summerhall, a networking event (Figure 19) in collaboration with the Edinburgh Hacklab and the ASCUS Art \& Science organisation enticed a crowd of all ages with artists, engineers, academics, scientists, students, and hobbyists in the audience. The events allowed the team members to present the work from differing perspectives based on the audience or theme, while highlighting various aspects of the multi-pronged project.

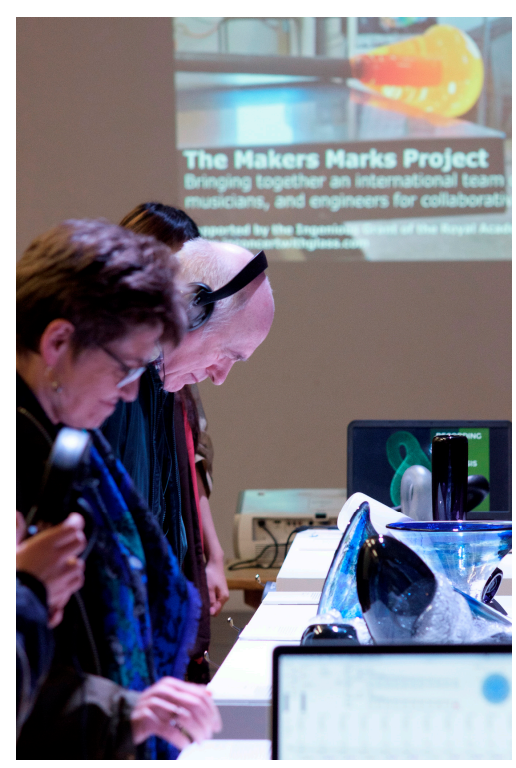

Figure 19. Audience members interacting with the Makers Marks objects in exhibition at the November 2016 Summerhall networking event, presented by the Makers Marks Collaborative in conjunction with Edinburgh Hacklab and ASCUS Art \& Science (Image: Alex Hall 2016). 


\section{Conclusions}

The interdisciplinary, collaborative project pushed the investigation, preservation, and dissemination of the sounds of the glassmaking process further than has been done before, as evidenced in the project's open access sound collection, processed with Binaural Auditory Scene Re-Synthesis, and the resulting virtual instruments and "Makers Suite" music composition. By sharing the sounds through digital technologies and art objects, the project reaches out to a wide, public audience. "Sounding Glass" and "Glass in Translation" convey the audio engineering and the engineers' visions as part of the glass art works, engaging the audience with the making process. Removing the sounds so completely from the glass workshop setting, and using them in these other forms, enabled study of them as sound data and sound art material in their own right. The project elevated the sounds, initially only the remains and exertion of the glass making process, and placed them before the team and audiences to consider as more than just makers marks.

Throughout the project, the team questioned the nature of glass, sound, blurred design roles, and the marks of the makers process. Instinctively and purposefully, the team members used metaphor as a communication bridge, both in language and in visuals. This allowed the group to articulate the new and the unfamiliar and to relay artistic processes to those outside of the disciplines. In retrospect, the team members realized that they used many more analogies in the work than had even been intended. This early work suggests that metaphor could be a useful tool for interdisciplinary, collaborative work in the studio to relay processes and visions, as well as to communicate across fields. More research, such as a design protocol study, is needed to document pointedly the use of metaphor, similes, and signs of analogical thinking during art and design, interdisciplinary, collaborative projects. Perhaps there are patterns of use that indicate the potential for working groups to succeed at their aims or to innovate.

The glass workshops also proved to be an ideal staging ground for the interdisciplinary work of the project. The versatile, ubiquitous material of glass, with its various physical properties and states, enabled associations across disciplines. Through these associations, commonalities among the team members were identified, which facilitated communication and ultimately, collaboration.

Author Contributions: Funding acquisition, project administration, supervision, writing-original draft: L.N.; software: D.F.; conceptualization, data curation, formal analysis, investigation, methodology, resources, visualization, writing-review and editing: L.N. and D.F.

Funding: This research was funded by a 2015 Ingenious Award from the Royal Academy of Engineering, grant number ING1415 \9\228.

Acknowledgments: The Makers Marks Collaborative is a multi-disciplinary team comprised of artists and engineers of various stripes, some of whom played numerous roles throughout the project work for the audio library, "Sounding Glass", and "Glass in Translation". For the purposes of this article, specific names were not attached to various subprojects and tasks, so as to highlight the roles rather than the individuals. Thank you to the entire team for your contributions to the project, and for your creativity, your patience, and your willingness to experiment! We would like to acknowledge each team member here: Lisa Naas (conceptualization, funding acquisition \& management, lead visual designer), David Faleris (lead composer/sound designer/computer programmer), Marcin Pietruszewski (lead recording/audio engineer), Al Bennett (lead electrical engineer/computer programmer), Ingrid Phillips (glass technician and artist), Alan Horsley (glass artist), Alkistis Terzi (photographer, videographer), Meg McGregor (glass assistant), Alessandro Mastroianni (sound designer/engineer), Antriksh Bali (sound designer/engineer), Xueran Chen (sound designer/engineer), Laura Reed (glass assistant), Zuzana Michlerová (sound designer/engineer), George Karpasitis (sound designer/engineer), Alberto Vásquez (sound designer/engineer), Cara Clay (sound designer/engineer), and Alex Hall (photographer). We are most grateful to the Royal Academy of Engineering for the Ingenious Award which enabled the project and public engagement with the engineering of our artworks. We would like to thank the Edinburgh College of Art for its generous hosting and support of this project, with special thanks to the Glass Department.

Conflicts of Interest: The authors declare no conflict of interest. 


\section{References}

Apel, Willi. 1972. Glass Harmonica. In Harvard Dictionary of Music. Cambridge: Harvard University Press, pp. 347-48.

Casacci, Max, and Daniele Mana. 2018. Glasstress. Available online: https:/ /badpandarecords.bandcamp.com/ album/max-casacci-daniele-mana-glasstress (accessed on 29 November 2018).

Corning Museum of Glass. 2002a. About Us. Available online: https://www.cmog.org/about (accessed on 14 January 2019).

Corning Museum of Glass. 2002b. Live Streaming. Available online: https:/ /www.cmog.org/programs/livestreaming (accessed on 14 January 2019).

Cray, Wesley D. 2014. Conceptual Art, Ideas, and Ontology. The Journal of Aesthetics and Art Criticism 72: $235-45$. [CrossRef]

DuoGlass. 2018. GlassDuo: Crystal Clear Music. Available online: http://glassduo.com/en/ (accessed on 14 January 2019).

Faleris, David. 2016. Makers Whirlpool. e-mail to Lisa Naas. June 10.

Feeney, Shawn. 2016. The Common Language of Visual and Musical Art. Available online: http://www. shawnfeeney.com/2016/03/the-common-language-of-visual-and-musical-art/ (accessed on 14 January 2019).

Fertig, Carrie. 2018. Torcher Chamber Arkestra. Available online: http://www.carriefertig.com/torcher-chamberarkestra (accessed on 29 November 2018).

Fondazione Berengo. 2018. Glass Fever. Contemporary Art in Glass. Available online: http://www. fondazioneberengo.org/ (accessed on 5 March 2016).

Goldie, Peter, and Elisabeth Schellekens. 2009. Philosophy and Conceptual Art. Oxford and New York: Oxford University Press.

Greary, James. 2011. I Is an Other: The Secret Life of Metaphor and How It Shapes the Way We See the World. London and New York: HarperCollins e-books.

Holyoak, Keith, and Paul Thagard. 1999. Mental Leaps: Analogy in Creative Thought. Woburn: The MIT Press.

Jerram, Luke. 2019. Keep on Turning. Available online: https://www.lukejerram.com/keep-on-turning/ (accessed on 14 January 2019).

Jones, Andy. 2017. The Essential Guide to Virtual Instruments. Available online: https:/ / www.musictech.net/ 2017/08/essential-guide-virtual-instruments / (accessed on 12 January 2019).

Klein, Dan. 2001. Artists in Glass. London: Mitchell Beazley.

Klein, Dan, and Ward Lloyd. 1991. The History of Glass. London: Black Cat.

Levitin, Daniel. 2007. This Is Your Brain on Music. London: Atlantic Books.

Makers Marks. 2016. In Conversation with Makers Marks. Available online: http:/ /www.inconcertwithglass. com/single-post/2019/01/29/In-Conversation-with-Makers-Marks / (accessed on 29 January 2019).

Mastroianni, Alessandro. 2016. Italian Nightmares e-mail to Lisa Naas via David Faleris. April 13.

Museo del Vetro. 2019. The Museum. Available online: http:/ / museovetro.visitmuve.it/en/il-museo/museum/ (accessed on 14 January 2019).

National Glass Centre. 2013. Free Glass Blowing Demos. Available online: http:/ / www.nationalglasscentre.com/ visit/onyourvisit/freeglassblowingdemonstrations / (accessed on 14 January 2019).

O'Connor, Erin. 2007. Hot Glass: The Calorific imagination of glassblowing in practice. In Practicing Cultures. Edited by Craig Calhoun and Richard Sennett. London and New York: Routledge.

Royal Academy of Engineering. 2019. Ingenious: Public Engagement Awards. Available online: https://www. raeng.org.uk/grants-and-prizes/ingenious-grant/ (accessed on 29 January 2019).

Schellekens, Elisabeth. 2009. The Aesthetic Value of Ideas. In Philosophy and Conceptual Art. Edited by Peter Goldie and Elisabeth Schellekens. Oxford and New York: Oxford University Press.

Soniccouture. 2018. Glass/Works. Available online: http:/ /www.soniccouture.com/en/products/28-rare-andexperimental/g14-glass-works / (accessed on 29 November 2018).

The Franklin Institute. 2018. Franklin's Glass Armonica. Available online: https:/ / www.fi.edu/history-resources / franklins-glass-armonica (accessed on 25 April 2018).

Tiso, Robert. 2018. Robert Tiso. Available online: http:/ / www.roberttiso.com/ (accessed on 14 January 2019). 
United Studio Effects. 2012. Sound Effects, Vol. 7. Available online: https:/ /www.amazon.com/Glass-BlowerFlame-Sounds-Igniting/dp/B008MIJS14 (accessed on 13 January 2019).

Vávra, Jaroslav Raimund. 1954. 5000 Years of Glass-Making: The History of Glass. Prague: Artia.

Venuti, Matt. 2018. The Hang Instrument. Available online: http:/ /www.mattvenuti.com/hang-instrument/ (accessed on 14 January 2019).

Vienna Symphonic Library. 2018. Glass Instruments. Available online: https://www.vsl.co.at/en/Elements/ Glass_instruments (accessed on 29 November 2018).

Zwicky, Jan. 2013. What is Lyric Philosophy? An Introduction. Common Knowledge. Available online: http: / / commonknowledge.dukejournals.org.ezproxy.is.ed.ac.uk/content/20/1/14.full.pdf + html (accessed on 5 March 2016). 